\title{
ANÁLISE INTEGRADA DOS INDICADORES SOCIOECONÔMICOS PARA O ESTUDO DO PROCESSO DE DESERTIFICAÇÃO NO POLO DE JEREMOABO-BA
}

\author{
Betiane Figueredo Vieira ${ }^{1}$; Jaimeval Caetano de Souza ${ }^{2}$ \\ 1. Bolsista PIBIC/Fapesb, Graduanda em Geografia, Universidade Estadual de Feira de Santana, e-mail: \\ betyane_figueredo@hotmail.com \\ 2. Orientador, Departamento de Ciências Humanas e Filosofia, Universidade Estadual de Feira de Santana, e-mail: \\ jaimeval.souza@hotmail.com
}

PALAVRAS-CHAVE: Indicadores socioeconômicos; Técnica de agrupamento; Desertificação.

\section{INTRODUÇÃO}

A Desertificação é um processo de degradação da terra em ambientes secos; resultante de variações climáticas e atividades humanas. O Polo de Jeremoabo (Novo Triunfo, Antas, Coronel João Sá, Pedro Alexandre, Santa Brígida, Jeremoabo, Canudos, Uauá, Chorrochó, Macururé, Rodelas, Glória e Paulo Afonso), localizado no nordeste baiano, de clima semiárido e árido é marcado por adversidades climáticas e ambientais. Somando-se a isso, a prática de atividades agropecuárias de forma extensiva o torna mais frágil ambientalmente, gerando susceptibilidade ao processo de desertificação. As consequências físicas da desertificação são devastadoras e se repercutem drasticamente na qualidade de vida da população local, sendo expressa então pelos problemas sociais e econômicos, como fome, pobreza, doenças, migrações, etc. Em vista disso, o presente trabalho teve como principal objetivo analisar os indicadores socioeconômicos de forma integrada para o estudo da desertificação no Polo de Jeremoabo-Ba.

\section{MATERIAL E MÉTODOS OU METODOLOGIA (ou equivalente)}

Foram realizados os seguintes procedimentos de pesquisa: primeiro foi realizada uma revisão bibliográfica sobre a temática, em seguida, fez-se o levantamento dos dados socioeconômicos na base de dados da SEI e do IBGE, com consequente aplicação da técnica de análise de agrupamento (cluster analysis); identificaram-se os conjuntos de variáveis com atuação semelhante a partir dessa técnica. Na etapa posterior foi feita a classificação dos municípios de acordo com os agrupamentos das variáveis, avaliou o perfil socioeconômico como indicador da desertificação, e por fim, interpretou, analisou e avaliou os resultados.

\section{RESULTADOS E/OU DISCUSSÃO (ou Análise e discussão dos resultados)}

Foram analisados dados de PIB, referente aos três setores da economia, PIB Per capita, Índice de Gini, Incidência da pobreza, Índice de Desenvolvimento Social (IDS) e Índice de Desenvolvimento Econômico (IDE). O conjunto de dados permitiu uma análise integrada da situação socioeconômica da região-Polo.

Quadro 1. PIB setorial (2012)

\begin{tabular}{|c|c|c|c|c|c|}
\hline \multicolumn{2}{|c|}{ PIB setorial } \\
\hline \multicolumn{2}{|c|}{ Agropecuária } & \multicolumn{2}{c|}{ Indústria } & \multicolumn{2}{c|}{ Serviços } \\
\hline $\begin{array}{c}\text { Maior } \\
\text { (valor) }\end{array}$ & Menor (valor) & Maior (valor) & Menor (valor) & Maior (valor) & $\begin{array}{c}\text { Menor } \\
\text { (valor) }\end{array}$ \\
\hline Jeremoabo & Novo Triunfo & Paulo & Macururé & Paulo Afonso & Macururé \\
\hline
\end{tabular}




\begin{tabular}{|c|c|c|c|c|c|}
\hline $\begin{array}{c}(21.987 \text { mil } \\
\text { reais })\end{array}$ & $\begin{array}{c}(1.522 \mathrm{mil} \\
\text { reais })\end{array}$ & $\begin{array}{c}\text { Afonso } \\
(1.629 .506 \\
\text { mil reais })\end{array}$ & $\begin{array}{c}(4.205 \mathrm{mil} \\
\text { reais })\end{array}$ & $\begin{array}{c}(645.120 \mathrm{mil} \\
\text { reais })\end{array}$ & $\begin{array}{c}(27.722 \mathrm{mil} \\
\text { reais })\end{array}$ \\
\hline
\end{tabular}

Os dados de PIB setorial demonstram que os municípios do Polo de Jeremoabo têm suas atividades econômicas voltadas principalmente para o setor de serviços, no qual se registra maiores produções, seguido então pelo setor industrial. Na maioria dos municípios, o desempenho da agropecuária não é tão significativo, demonstrando ter pouca participação na produção de riquezas. Paulo Afonso se destaca com maior PIB industrial e também de serviços. Isso se deve as atividades da CHESF - Companhia Hidrelétrica do São Francisco. O PIB agropecuário desse município é pouco significativo, isto é, no valor de 9.794 mil reais. Macururé possui o menor PIB no setor industrial e também no de serviços. Jeremoabo é o município com maior produção do Polo no setor agropecuário. Já o município de Novo Triunfo registrou menor taxa do PIB nesse setor.

Tabela 1. PIB Per capita

\begin{tabular}{ll}
\hline Maior (valor) & Menor (valor) \\
\hline Paulo Afonso & Novo Triunfo \\
(21.381,57 reais) & $(2.767,52$ reais) \\
\hline
\end{tabular}

Tabela 2. Índice de Gini

\begin{tabular}{ll}
\hline Maior (valor) & Menor (valor) \\
\hline Paulo Afonso & Pedro Alexandre \\
$(0,5)$ & $(0,35)$ \\
\hline
\end{tabular}

Paulo Afonso se destaca como o mais desenvolvido economicamente, apresentando maior PIB Per capita do Polo, e também apresenta o maior índice de Gini do Polo. É interessante notar que esse município possui melhores condições econômicas de que os outros municípios, apresentando maior desempenho no PIB, porém, apresenta também maior desigualdade de renda na população.

Tabela 3. Incidência da pobreza

\begin{tabular}{ll}
\hline Maior (valor) & Menor (valor) \\
\hline $\begin{array}{l}\text { Coronel João Sá } \\
(56,67 \%)\end{array}$ & $\begin{array}{l}\text { Chorrochó } \\
(28,15 \%)\end{array}$ \\
\hline
\end{tabular}

Tabela 4. IDE

\begin{tabular}{ll}
\hline Maior (valor) & Menor (valor) \\
\hline Paulo Afonso & Coronel João Sá \\
$(5.070,82)$ & $(4.948,99)$ \\
\hline
\end{tabular}

Os municípios do Polo apresentam um elevado percentual de incidência da pobreza. Coronel João Sá é o de maior taxa de incidência da pobreza e Chorrochó é o município com menor percentual. Paulo Afonso registrou também um maior IDE em relação aos demais municípios. Coronel João Sá é o município com menor IDE.

Tabela 5. IDS

\begin{tabular}{ll}
\hline Maior (valor) & Menor (valor) \\
\hline Paulo Afonso & Novo Triunfo \\
$(5.129,42)$ & $(4896,77)$ \\
\hline
\end{tabular}

Paulo Afonso apresenta maior índice de desenvolvimento social e Novo Triunfo possui menor IDS. 


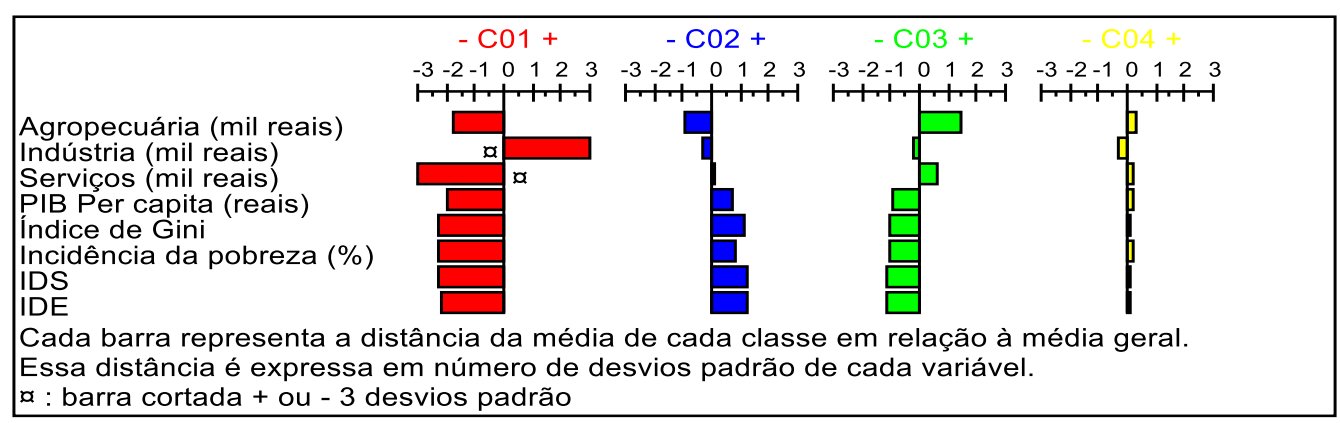

Figura 1. Perfis médios das quatro classes selecionadas

O primeiro grupo (vermelho) é formado com PIB no setor secundário predominante, ou seja, a média desse grupo em relação ao PIB industrial é maior que a do Polo. As barras das outras variáveis - PIB primário, PIB terciário, PIB Per capita, Índice de Gini, Incidência da pobreza, IDS e IDE - estão à esquerda, portanto, as médias desse grupo referente a essas variáveis são inferiores a do todo. Contudo, é possível afirmar tratar-se de um grupo que apresenta expressivo nível de industrialização com baixa participação nos setores de agropecuária e serviços, caracterizado, face a industrialização, pela redução da pobreza mas com índices de desenvolvimento econômico e social bastante baixo e do PIB per capita também baixo em relação ao conjunto do Pólo. No grupo destacado em azul as barras de todas as variáveis com exceção do PIB industrial estão à direita, o que significa que as médias dessas variáveis desse grupo são superiores à do todo, embora muito baixa. Como a barra que designa o PIB industrial está à esquerda, indica que esse grupo possui uma média desse PIB menor que a do todo. Isso indica que a produção do setor secundário não é significativa nesse grupo. Portanto este grupo demonstra predominância de atividades voltadas para os setores da agropecuária e serviços, porém muito próximo da média de todo conjunto do pólo. Verifica-se um acentuado nível de pobreza com PIB per capita, IDS e IDE um pouco acima da média do todo. No grupo verde constata-se melhores participação dos setores agropecuário e serviços e também uma relativa baixa incidência da pobreza. Por outro lado, observa-se redução no PIB per capita e nos índices de desenvolvimento econômico e social. No grupo amarelo, verifica-se que o PIB industrial é pouco significativo e que todas as variáveis com barras à direita estão acima da média do todo. O mapa que segue representa cada agrupamento de municípios formado.

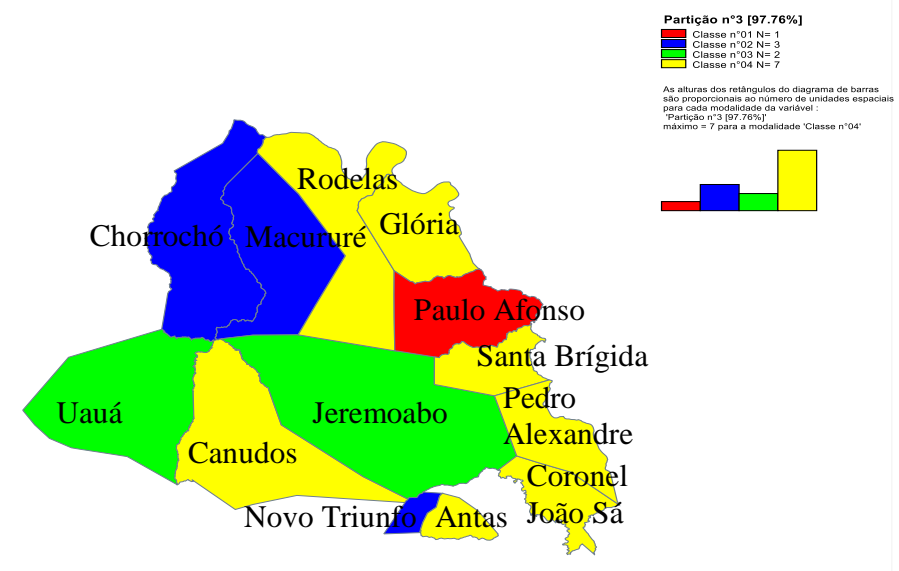




\section{CONSIDERAÇÕES FINAIS (ou Conclusão)}

A análise integrada dos dados socioeconômicos permitiu verificar que os municípios do Polo em maior ou menor grau apresentam forte concentração de renda, além disso, uma alta incidência de pobreza. Com a utilização da técnica de agrupamento, foi possível identificar os municípios que apresentam características semelhantes e também as diferenças entre os grupos. Paulo Afonso se diferencia significativamente dos demais municípios, se constituindo como município mais industrializado e desenvolvido economicamente, formando unicamente um grupo. Uauá e Jeremoabo, os dois juntos também forma um grupo, apresentando características similares, como por exemplo, a predominância da atividade e produção agropecuária. No geral, os grupos apresentam o mesmo grau de vulnerabilidade socioeconômica ao processo de desertificação.

\section{REFERÊNCIAS}

BAHIA, Superintendência de Estudos Econômicos e Sociais da Bahia/SEI. Índices municipais de desenvolvimento econômico e social do Estado da Bahia. 2006.

BARBOSA, M. A. Desertificação no semi-árido baiano. Salvador: Seplantec, CAR, Projeto Áridas-Bahia, Mimeogr. 1995.

BRASIL, Atlas das áreas susceptíveis à desertificação do Brasil / MMA, Secretaria de Recursos Hídricos, Universidade Federal da Paraíba; Marcos Oliveira Santana, organizador. Brasília: MMA, 2007.

BRASIL. Ministério do Meio Ambiente. Programa Nacional de Combate à Desertificação e Mitigação dos Efeitos da Seca - PAN-Brasil. Brasília, DF: Ministério do Meio Ambiente; Secretaria de Recursos Hídricos, 2005.

CONTI, J. B. A questão climática do nordeste brasileiro e os processos de desertificação. Revista Brasileira de Climatologia, 2005.

GIRARDI, E. P. Manual de utilização do programa PHILCARTO. 2007.

HARE, F. K.; WARREN, A.; MAIZELS, J. K.; KATES, R. W.; JOHNSON, D. L.; HARING, K. J.; GARDUÑO, M. A. Desertificação: causas e consequências. Fundação Calouste Gulbenkian, Lisboa 1992.

INSTITUTO BRASILEIRO DE GEOGRAFIA E ESTATÍSTICA (IBGE). Censo 2010. Disponível em: http://www.ibge.gov.br. Acesso em: 10 fev. 2014.

MATALLO JR., H. Indicadores de Desertificação: histórico e perspectivas. Cadernos da UNESCO, Brasil, série Meio Ambiente e Desenvolvimento, v.2. Brasília: UNESCO, 2001.

RODRIGUES, V. et al. Avaliação do quadro da desertificação no Nordeste: diagnóstico e perspectivas. Fortaleza. ICID, 1992.

SALES, M. C. L. Evolução dos Estudos de Desertificação no Nordeste Brasileiro. GEOUSP-Espaço e Tempo, São Paulo, No 11, pp.115-126, 2002.

VASCONCELOS SOBRINHO, J. Desertificação no Nordeste do Brasil. Recife: Fadurpe/UFRPE. 2002. 